\title{
Tocata Aberta
}

A Internet e os processos colaborativos

José Luiz Kinceler

Francis Albrecht Pedemonte

Palavras-chave: Arte Relacional Complexa, Descontinuidade, Música, Internet, Processo Colaborativo

Resumo: A proposta Tocata Aberta, parte integrante do projeto Vinho Saber, Arte Relacional em sua forma Complexa, procura articular encontros musicais, usando a internet como meio de disseminar a idéia da música livre. Este artigo analisa como a evolução tecnológica das últimas décadas proporcionou novas propostas artísticas em processos colaborativos e explica a forma que nos utilizamos destes recursos para gerar descontinuidades criativas no cotidiano..

Projeto de Pesquisa: Vinho Saber-Arte Relacional em sua forma Complexa - CEART

Orientador: José Luiz Kinceler, departamento de Artes Visuais

bolsistas: Aline Goedert Volkmer (PROBIC), Francis Albrecht Pedmonte (PROBIC)

Acadêmicos participantes: Helton Patricio Matias

DAPesquisa, Florianópolis, v.3 n.5, p.139-151, 2008. 


\section{Introdução}

Os tema central deste artigo é a relação entre a internet e a música, que se interligam através da proposta Tocata Aberta.

Desde quando criada, há quase quarenta anos, a internet tornou-se parte da cultura de massa do novo século. As novas tecnologias possibilitaram uma autonomia jamais imaginada. Ferramentas poderosas culminaram com o surgimento de uma série de novas proposições audiovisuais, ampliando o grau de participação do espectador. De que forma esta gama de possibilidades pode contribuir para o campo da Arte Relacional Complexa? Qual a relação entre as experiências e informações digitais com as vivências e experiências reais?

Entre as mídias que expandiram no século passado, a internet foi a primeira a possibilitar uma utilização participativa. Evidente que ela não da conta de substituir a experiência real. No entanto, é possível estabelecer um intercâmbio, onde nos servimos das ferramentas virtuais de produção, comunicação para auxiliar-nos com essa experiência autêntica.

No artigo "Notas sobre a experiência e o saber de experiência" Jorge Larrosa Bondía questiona a respeito da diferença entre estar informado e o valor da experiência:

Nunca se passaram tantas coisas, mas a experiência é cada vez mais rara. Em primeiro lugar pelo excesso de informação. A informação não é experiência. E mais, a informação não deixa lugar para a experiência, ela é quase o contrário da experiência, quase uma antiexperiência. Por isso a ênfase contemporânea na informação, em estar informados, e toda a retórica destinada a constituir-nos como sujeitos informantes e informados; a informação não faz outra coisa que cancelar nossas possibilidades de experiência. (...) Depois de assistir a uma aula ou a uma conferência, depois de ter lido um livro ou uma informação, depois de ter feito uma viagem ou de ter visitado uma escola, podemos dizer que sabemos coisas que antes não sabíamos, que temos mais informação sobre alguma coisa; mas, ao mesmo tempo, podemos dizer também que nada nos aconteceu, que nada nos tocou, que com tudo o que aprendemos nada nos sucedeu ou nos aconteceu. ${ }^{1}$

BONDÍA, Jorge Larrosa. Notas sobre experiência e o saber de experiência. (p 21, 22 ) download aqui 
Embora a Tocata Aberta propicie a vivência real, ela não descarta a utilidade da informação gerada por ela, ao contrário, se utiliza dela para gerar novas experiência em forma de outros encontros musicais livres.

A Tocata aberta disponibiliza instrumentos musicais instalados em um espaço incomum. A proposta é simples e direta: "Fazer um som”! O objetivo da tocata é desinibir as pessoas e possibilitar a criação musical para aqueles que não necessariamente dominam esta linguagem. A premissa principal é de que todo ser humano é um músico natural, tendo em vista que, antes do nascimento, o primeiro dos sentidos a ser experimentado é o Som.

A intenção é fazer como que todos os presentes se permitam manter uma relação sincera com a música, sem medo de se expressar. Tocar algum instrumento musical é como falar sem palavras. Não é preciso saber ler ou escrever partitura para entender a linguagem sonora, pois estamos constantemente associando imagens, sons, aromas, sabores, e texturas em nosso cotidiano. Trata-se de propor um estreitamento entre a música e as pessoas. Quão fértil pode ser uma "relação musical" quando ela se estende para fora deste encontro? Quão inusitados e originais podem ser os improvisos?

A “Tocata Aberta como informação" é completamente diferente da experiência compartilhada entre os presentes. No entanto, esta informação veiculada de maneira correta pode incentivar novas experiências independentes. Para tanto foram registrados encontros ao longo do primeiro semestre de 2008 para a criação de um CD e de um DVD que serão disponibilizados gratuitamente na internet. O registro da experiência tem como objetivo disseminar esta idéia, estimular novas experiências e o intercâmbio entre este material. A internet funciona como agente mediador entre os acontecimentos reais em diferentes lugares. O internauta, ao assistir um dos vídeos do evento, é convidado a realizar o seu próprio som, veiculando-o na rede, agindo como multiplicador.

\section{Tecnologia a serviço da arte e da vida}

A Internet foi criada por militares nos anos 70, e permaneceu durante duas décadas sob domínio exclusivo deles. Na época, não se supunha que o computador seria uma ferramenta tão difundida. Na década de 90, a explosão dos micro-computadores e, por conseguinte a 
popularização da "net", iniciou um processo jamais imaginado. O que anteriormente se resumia a um veículo de comunicação totalmente restrito, estaria disponível para qualquer um que pudesse dispor de um navegador e uma linha telefônica.

Desde então, os processadores tornaram-se menores, os softwares velozes e acessíveis. A virada do século coroou o computador como a nova mídia, já que ele aglutinou todas as demais, como rádio, televisão, jornal e telefone, e gerou novas possibilidades como a vídeoconferência.

Em seu ensaio TAZ ( Temporary Autonomous Zone ), Hakim Bey discorre a respeito da função da net na formação e articulação das Zonas Autônomas Temporárias (TAZ). No entanto, afirma Bey, que a a TAZ aconteceu, está acontecendo e vai acontecer com ou sem o computador. Segundo ele,

A TAZ deseja, acima de tudo, evitar a mediação, experimentar a existência de forma imediata. A essência da TAZ é "peito-a-peito", como dizem os sufis, ou cara-a-cara. Mas, a essência da web é mediação, onde as máquinas são nossos embaixadores - a carne é irrelevante exceto como um terminal, com todas as conotações sinistras do termo. ${ }^{2}$

Em outras palavras, Bey afirma que, embora a net tenha importante papel no desenvolvimento das TAZ's, a rede não passa de uma mediadora, e que ainda não é possível vincular a virtualidade que ela propicia das necessidades reais, ou da real liberdade de ação e expressão. Bey afirma:

Francamente, eu já possuía muitos dados para alimentar meus sentidos e percepções: livros, filmes, TV, teatro, telefone, correio, estados alterados de consciência, e daí por diante. Preciso realmente de um PC para obter ainda mais informações desse tipo? Você me oferece informação secreta? Bem... talvez. Fico tentado, mas eu exijo segredos maravilhosos, e não apenas os números de telefones que não estão na lista ou trivialidades sobre a polícia e os políticos. Sobretudo, quero que os computadores me forneçam informações relacionadas a bens reais (...) Agora, já que acuso os hackers e os usuários das BBS de possuírem uma irritante vacuidade intelectual, devo descer das nuvens barrocas da teoria e da crítica e explicar o que quero dizer com bens reais. (...) Em suma, suponha que eu esteja cansado de mera informação, do fantasma dentro da máquina. De acordo com vocês, os computadores já deveriam ser capazes de possibilitar a realização dos meus

BEY, Hakim . TAZ: zona autônoma temporária . Tradução de Renato Rezende \& Patrícia Decia. - São Paulo: Conrad Editora do Brasil, 2001. (ColeçãoBaderna) (fonte: Rizoma.net) 
desejos por comida, drogas, sexo, sonegação fiscal. Então, qual é o problema? Por que isso não está acontecendo? ${ }^{3}$

É importante pensar que este texto foi escrito nos anos 80, antes da explosão digital e da fácil acessibilidade da rede, anteriormente citada. Nesta época, os usuários resumiam-se a alguns milhares de privilegiados, centralizados nos países de primeiro mundo. Seu conteúdo se restringia somente a textos, e poucas imagens, em baixíssima resolução. A virtualidade era muito pobre e irreal, de fato muito pouco atraente. Nos dias atuais, esse quadro se reverteu. Temos acesso a imagens, músicas, filmes, vídeos, jogos, editores de imagem, som, vídeo, 3D, animação, e tudo mais o que se pode imaginar.

A resposta para os anseios de Bey só pôde vir com o tempo: a internet expandiu-se, proporcionalmente a sua popularização. $\mathrm{O}$ aumento assustador do número de usuários criou uma demanda, e a cada instante surge uma nova tecnologia que atrai mais usuários. A internet se tornou um fenômeno, perturbador e incontrolável. E assim como a rede permitiu interações, digamos assim, "bem vistas” para a sociedade, ela também dá suporte para as mais bizarras operações.

Ao contrario do que Bey supunha, hoje em dia a internet está repleta de TAZ's. O sistema já não é rápido e eficaz o suficiente para controlar a tudo e a todos. Por isso essas zonas são temporárias, pois contam com a lentidão do sistema; usam este atraso a seu favor, e quando descobertas, rapidamente mudam de endereço. Este tempo é mais do que o necessário para repassar informações para multiplicadores. Tantos, que se torna quase impossível rastreálos. Hackers se multiplicam. Indústrias de dimensões gigantescas, como a fonográfica e a cinematográfica, estão definhando gradativamente. Qualquer um pode baixar um filme em alta qualidade, antes mesmo de ele ser lançado no cinema. As pessoas estão se questionando, por que comprar, se eu posso ter de graça? Governos tentam desesperadoramente incorporar um aspecto de marginalidade a esses atos, mas nem eles mesmos sabem ao certo como controlar e punir quem se deleita com estas facilidades. É difícil imaginar sequer uma pessoa que tenha usado a rede nos últimos anos sem fazer ao menos um "download ilegal". Cada cidadão se tornou um pirata em potencial.

BEY, Hakim . TAZ: zona autônoma temporária . Tradução de Renato Rezende \& Patrícia Decia. - São Paulo: Conrad Editora do Brasil, 2001. (ColeçãoBaderna) (fonte: Rizoma.net) 
E quem tem a ganhar com isso tudo? O sujeito comum, que goza de todo esse banquete informação e prazer. O que diria Bey, hoje em dia, a respeito disso tudo? Não seriam estas coisas que ele julgara não satisfazer na internet daqueles dias? Será que hoje em dia a rede se apresenta sedutora a seus olhos?

Neste momento, o consciente coletivo já assimilou, não só a rede de computadores mas uma infinidade de outras dimensões, como uma parte da realidade, e não algo paralelo a ela. Atreveria-me a dizer que, para alguns, estas dimensões paralelas já substituíram uma possível realidade. Numa sociedade do espetáculo a simulação se mostra muito mais atraente do que um cotidiano medíocre.

No entanto, ao mesmo tempo em que a máquina auxilia nos processos de criação, a rede propicia uma delicada situação em relação às questões autorais. A infinita multiplicação de informações descaracteriza a obra. O que diferencia o original da cópia? Acrescenta-se, retirase e modifica-se o que quiser, da maneira que quiser e a hora que quiser. Nada é assegurado neste território livre, que dirá a garantia da autenticidade da autoria de algum texto ou imagem. Em seu artigo “Arte em rede web e processos estéticos híbridos”, Maria Amelia Bulhões discorre a respeito do assunto:

As novas tecnologias, com base no automatismo numérico, redesenham a figura do sujeito nos seus intercâmbios com o real e o imaginário, assim como em suas relações com o coletivo. A partir da análise de algumas dessas propostas artísticas pode-se explorar as diferentes formas como artista e usuários reconfiguram suas relações, colocando em cheque a tradicional noção de autoria. ${ }^{4}$

É curiosa a forma com que a autora usa o termo "Usuários" para designar os que outrora eram chamados espectadores. É um termo corriqueiro quando usado para nomear as pessoas conectadas a rede, mas se mostra muito potente se interpretado ao pé da letra. Não estamos mais contemplando a arte, mas usando-a. Esta nova relação que ela se refere, está em constante mutação, visto que a interatividade é cada vez maior. O artista "usa" o espectador, e este por sua vez "usa" o artista e sua obra, enquanto ambos "usam" o sistema para tornar esta comunicação possível. É uma relação de colaboração, em que cada elemento se torna

\footnotetext{
${ }^{4}$ BULHÕES, Maria Amélia. Arte em rede web e processos estéticos híbridos, $16^{\circ}$ Encontro Nacional da Associação Nacional de Pesquisadores de Artes Plásticas Dinâmicas Epistemológicas em Artes Visuais Florianópolis - setembro de 2007
} 
indispensável para os demais. "O artista não atua mais como o criador único de sua obra, mas divide com o usuário esse trabalho e responsabilidade." conclui.

No mesmo artigo, a autora cita uma série de atividades colaborativas desenvolvidas a partir da internet, como o projeto Post Urbano, do coletivo argentino Wokitoki. Nele, os usuários usam o Googlemaps para identificar certos pontos de Buenos Aires e contar alguma história intima do seu cotidiano relacionada a estes lugares. Estes relatos são fixados em "cartazes digitais" que se tornam disponíveis ao público, criando um "mapa" de informações . Esta proposta ilustra bem esta tríplice articulação entre Autor (artista), Usuário (internauta) e Sistema (Googlemaps) anteriormente citada. Embora tenha sido idealizada por uma das partes, somente com a intervenção das demais a obra se realiza. Não há um objeto final, este mapa está em constante construção. "A imagem sempre mutável, portanto momentânea, exige mudanças radicais no pensamento atual, assimilando a ausência de passado e futuro, congelada em seu presente permanente” afirma Maria Amélia.

No livro "Estética De La Emergência”, Reinaldo Laddaga cita outras importantes articulações via internet, como o projeto "Translation Map” de Sawad Brooks e Warren Sack. Se trata do "protótipo de um sistema desenhado para facilitar traduções colaborativas", em que o usuário propõe uma palavra, frase ou texto a ser traduzido, e o sistema a encaminha para diversos fóruns de discussão em lugares onde seja comum o uso das línguas “origem” e “destino" da tradução.

Quando se envia uma mensagem com o sistema de Translation Map lhe pedirá que ajude a escolher a rota da mensagem. Para navegar na rota escolhida, a mensagem se publica em fóruns de discussão pública geograficamente específicos em linha. (Em Usernet, Em Yahoo, etc.). Uma vez enviada, a mensagem será posta no site da web do Translation Map e mandado aos fóruns de discussão pública escolhidos. A mensagem estará publicamente disponível, e se publicará em diversas áreas da internet. ${ }^{5}$

Segundo Laddaga, esta estratégia cria uma espécie de escrita colaborativa, criando uma relação entre os autores e tradutores.

Em todos estes exemplos, estão contidos os principias pilares de sustentação da arte relacional em sua forma complexa, segundo a qual o processo criativo em arte é uma atitude

5 LADDAGA, Reinaldo, . Estética de la emergencia . Buenos Aires: Adriana Hidalgo editora, 2006. 
ético-estética capaz de, ao identificar oportunidades no contexto social, provocar descontinuidades estéticas e reflexivas no cotidiano que permitam produzir novas subjetividades, sejam da ordem do singular ou do coletivo. Fazendo uso de referentes, modela através da reinvenção do jogo representacional em arte, processos de convívio, de diálogo e contaminação nos quais as relações sociais pedem ser desconstruídas.

\section{A proposta "Tocata Aberta"}

Em parceria com a colega Aline Goedert Volkmer, o professor Dr. José Luiz Kinceler e demais membros do grupo de pesquisa, desenvolvemos uma proposta chamada Tocata Aberta. Nesta pude experimentar algumas possibilidades do processo colaborativo, dentro e fora da rede. Por pertencer a uma geração totalmente adaptada ao meio digital, para mim o interessante é perceber as relações que se criam fora dele, e as maneiras de documentá-las e sintetiza-las para a inserção no mesmo.

Esta proposta iniciou-se com a reunião de pessoas que gostam de música e se interessem na confecção de instrumentos. Em encontros semanais, aprendemos a confeccionar instrumentos de cerâmica, como Tambores, Djambés, Ocarinas e Violões em cerâmica ao longo de um semestre. Neste primeiro momento, já foi possível observar algumas situações de estreitamento entre os presentes, que interagiam e colaboravam entre si. Como não foi pré estabelecido nenhum padrão na confecção das peças, embora coletiva, a produção obteve um resultado heterogêneo, o que permitiu uma diversidade de sons.

No fim do semestre, realizamos uma queima das peças de cerâmica no forno da comunidade Batuel Cunha, no Rio Tavares. Neste mesmo dia, foi realizada, de maneira improvisada, a nossa primeira tocata. (2o capítulo do DVD) Nesta época, ainda não sabíamos de que forma articular os encontros, e logo pudemos perceber que, de certa forma, era irrelevante, tendo em vista que a tocata se formou naturalmente. Sendo assim, me senti livre para me preocupar somente com a maneira com a qual registraríamos esses acontecimentos. 


\section{Os encontros da "Tocata Visual Aberta"}

Em todos os encontros, organizamos uma estrutura audiovisual completa: aparelhos de DVD e projetores de vídeo, que usamos para exibir vídeos de artistas; instrumentos musicais diversos, que variavam de acordo com cada evento; e aparelhagem para gravação profissional de áudio, e câmeras digitais portáteis para gravação de vídeo.

Juntos esses elementos compunham uma forte ferramenta geradora de descontinuidades. Os vídeos atraiam e mantinham a atenção das pessoas que passavam. Com essa aproximação, facilitava o entendimento imediato do mecanismo da tocata, nos poupando de ter que fazê-lo oralmente. O que de fato quebraria a "mágica" do acontecimento

Logo, as pessoas se viam envolvidas pela música, e ficavam mais à vontade para "se expressar" musicalmente. Passados estes estados de "atração", "encantamento" e "entrega", surgia a curiosidade, a necessidade de racionalizar, saber de fato o que estava acontecendo.

A tecnologia estava presente em praticamente todas as etapas deste processo criativo: desde as máquinas da oficina de escultura que auxiliaram a fazer os aros de metal para a fixação das peles dos instrumentos, até os computadores, microfones e equipamentos de áudio e vídeo das tocatas.

No primeiro evento "oficial", realizado na arena central do ceart, poucas pessoas compareceram. Apenas algumas poucas fotos e vídeos foram registrados. O áudio desta tocata foi descartado, por falta de qualidade... Na ocasião, haviam tambores, chocalhos e um violão à disposição, uma configuração simples. Ainda assim, pudemos registrar alguns momentos interessantes, mas a claridade, o número reduzido de participantes e o "aparato" exagerado provavelmente inibiu a participação. Já a qualidade foi comprometida por problemas na manipulação do equipamento

A tocata seguinte, mudou para o prédio das artes plásticas, e já contou com um número maior de pessoas e instrumentos, mas ainda enfrentamos problemas com o registro do áudio. No entanto, a música já evoluiu consideravelmente, algumas excelentes improvisações, extremamente percussivas. 
A próxima tocata foi marcada fora da UDESC, em um campeonato de sinuca organizado por uma colega, em um bar das proximidades. Nenhum áudio foi registrado, somente vídeos. Foi interessante perceber como mais uma vez o ambiente ditou as regras: a tocata do bar foi a mais descontraída, sem pretensões. Observei também que, com a presença de mais pessoas, essa tocata teve maior número de composições da música popular, ao invés de longas improvisações instrumentais.

$\mathrm{Na}$ semana seguinte, finalmente conseguimos uma boa harmonia entre todos os participantes, e o resultado foi surpreendente. Fizemos a captação de áudio estereofônica (em 2 canais) com 4 microfones, que pode ser conferida no CD e no DVD.

O efeito estéreo cria uma ilusão espacial no ouvinte, que consegue situar os instrumentos em diferentes regiões de seu campo auditivo. (Mais uma vez a tecnologia, situando o ouvinte no local...)

Desta tocata, foram extraídas varias passagens do $\mathrm{CD}$ e do DVD. Ela foi imprescindível para observarmos a evolução do dispositivo relacional, que a essas alturas, de certa forma, começava a dar passos mais largos. A partir deste ponto, comecei a prestar atenção em todas as passagens, que apresentavam elementos mais sofisticados, gerados ao acaso, que poderiam ser de grande utilidade em um estudo para releitura futura. Nesta tocata, já podemos notar a presença de um instrumento elétrico, a guitarra entre os violões e tambores acústicos. Trata-se de uma tocata transitória, com diferentes elementos em comunhão.

No evento seguinte, ousei levando um número maior de instrumentos: Bateria, microfone para a vocal, guitarra e baixo elétricos. Queria ver como esses elementos mais altos, complexos e evidentes no campo sonoro se comportavam em meio às improvisações coletivas com diversas pessoas e tambores em profusão. Uma maneira interessante de ver como funciona a "permissão", onde percebemos que, quem melhor ouvia, mais corretamente se postava diante da música. No entanto, quando alguém se perdia do foco coletivo na posse de um desses instrumentos de maior "força", acabava por desconcentrar os demais e "deixar morrer" a música. Pela primeira vez, a tocata contou com uma música cantada, cuja letra foi improvisada na hora. 
Esta foi a tocata que rendeu o maior tempo de áudio gravado, somando 2 horas e 30 minutos, no entanto, embora de boa qualidade, a gravação foi feita em mono (1 canal), mais uma vez por dificuldades técnicas. Logo, neste registro não podemos situar os instrumentos no ambiente. A acústica do prédio é cheia de reverberações e excessos, o que contribuiu para uma sonoridade mais forte, pulsante e saturada.

A tocata seguinte manteve as mesmas características timbrais e os mesmos instrumentos da anterior, no entanto, com maior refinamento melódico. Neste dia, novamente captação mono, que iniciou 1 hora depois do inicio do evento. Nenhum vídeo ou foto foi registrado, o que aconteceu por acaso, mas veio a calhar, pois daqui saíram varias músicas para o CD.

Finalmente no dia 19 de junho realizamos nossa última tocata do semestre, em um restaurante no canto da lagoa. Tecnicamente melhor resolvido, contando com algumas das pessoas mais constantes nas tocatas, e em um lugar com a acústica privilegiada, foi uma das tocatas mais refinadas registradas. A sessão rítmica ficou por conta dos tambores, pandeiros, chocalhos e afins. Nas melodias, guitarra e violão. Além das improvisações, surgiu uma interessante releitura para o clássico Asa Branca de Luiz Gonzaga, com harmonia de tempero oriental, explorando sonoridades menores... $\mathrm{Na}$ minha opinião, um dos momentos mais sublimes.

\section{Pós Produção}

Em posse de todo esse material, me reuni com minha colega Aline para começar as edições. Por se tratar de um tema empírico, houve grande preocupação para que o material possa traduzir a experiência sem muitas distorções.

O resultado final: $1 \mathrm{CD}$ de áudio com os melhores momentos das tocatas; $1 \mathrm{DVD}$ mostrando todo o processo; 1 relatório imagético; além dos artigos e do Site do Vinho Saber, onde disponibilizamos todo este conteúdo on-line gratuitamente, para livre veiculação e utilização sem fins lucrativos. 
Sem a internet, esta veiculação perderia o sentido, pois não haveria possibilidade de resposta por parte do público, que tem acesso as mesmas ferramentas que utilizamos na pós produção, ou seja, plenas condições técnicas de produzir áudio ou vídeo com uma qualidade muito boa.

Porem, ressalto que o importante não é a fidelidade do material, mas sim, o entendimento da proposta. Por mais que nos esforcemos para registrar imagens e sons, o que realmente vale neste dispositivo jamais poderá ser materializado: como realmente se deram as relações e quais foram as diferentes experiências pessoais de cada envolvido. Ainda não podemos digitalizar ou materializar sensações, ainda mais nesta magnitude de abstração. $\mathrm{O}$ que aconteceu nesses dias, só quem estava lá poderá saber ao certo. É de suma importância que o internauta esteja ciente disso, pois assim ele entenderá que só vivendo sua própria experiência ele saberá o que é uma tocata.

\section{Considerações finais}

Somente com o pleno funcionamento do mecanismo envolvendo o artista, a rede e o usuário a Tocata Aberta faz sentido: $\mathrm{O}$ artista planta a idéia, mostra as ferramentas disponíveis e agência as respostas; a rede disponibiliza gratuitamente não só informações, mas ferramentas de criação e comunicação; os usuários tem acesso à todo o material do site, para livre utilização e veiculação, além de guias explicativos à respeito da confecção de instrumentos em cerâmica, esquemas de áudio e vídeo, operação dos sistemas digitais, etc.

A Tocata Aberta é um ciclo que se renova constantemente através das interdependências "homem - máquina - homem", cada participante desde processo é como uma engrenagem complexa. Nós podemos dar o pontapé inicial, mas o que virá a se tornar esta proposta só o tempo poderá dizer.

O campo abordado neste artigo ainda permanece pouco explorado se proporcional a sua expansão e influência na forma de viver do novo século. É importante permanecer sempre atento as transformações e como reagimos a elas. No momento em que nos submetermos a máquina e esquecermos dos verdadeiros sabores da vida, das experiências reais, das sensações, sentimentos e emoções, perderemos nossa identidade. No entanto, sempre que 
pudermos articular uma comunicação equilibrada entre o real e o virtual em prol do bem comum, somaremos experiências de vida e multiplicaremos boas idéias.

Da Tocata Aberta para a rede, muita energia, subjetividade em momentos únicos... Agora, só esperamos colaborações!

\section{Bibliografia}

- BEY, Hakim . TAZ: zona autônoma temporária . Tradução de Renato Rezende \& Patrícia Decia. - São Paulo: Conrad Editora do Brasil, 2001. (ColeçãoBaderna)

- BOURRIAUD, Nicolas . Estética Relacional . Buenos Aires: Adriana Hidalgo editora, 2006.

- LADDAGA, Reinaldo, . Estética de la emergencia . Buenos Aires: Adriana Hidalgo editora, 2006.

- BULHÕES, Maria Amélia. Arte em rede web e processos estéticos híbridos , $16^{\circ}$ Encontro Nacional da Associação Nacional de Pesquisadores de Artes Plásticas Dinâmicas Epistemológicas em Artes Visuais - Florianópolis - setembro de 2007

- O movimento da wikiarte defende que todos sejam criadores na internet. Editoria: Comunidade, Abril 2006. Link Aqui

- FIORELLI, Marilei Catia. Arte interativa e colaborativa em rede: estudo de caso do coletivo pernambucano Re:combo. Link Aqui

- BONDÍA, Jorge Larrosa. Notas sobre experiência e o saber de experiência. Universidade de Barcelona, Espanha 2002. Tradução de João Wanderley Geraldi. Universidade Estadual de Campinas, Departamento de Lingüística. Download Aqui 